\title{
BMJ Open Food insecurity and its predictors among lactating mothers in North Shoa Zone, Central Ethiopia: a community based cross-sectional study
}

\author{
Lemma Getacher (D) , ${ }^{1}$ Gudina Egata, ${ }^{2}$ Yared Asmare Aynalem (D) , ${ }^{3}$ Abebaw Molla, ${ }^{4}$ \\ Adane Tesfaye, ${ }^{5}$ Haimanot Abebe (D) , ${ }^{6}$ Wubet Alebachew Bayih (D) , \\ Samuel Derbie Habtegiorgis (10 ${ }^{8}$
}

To cite: Getacher L, Egata G, Aynalem YA, et al. Food insecurity and its predictors among lactating mothers in North Shoa Zone, Central Ethiopia: a community based cross-sectional study. BMJ Open 2020;10:e040627. doi:10.1136/ bmjopen-2020-040627

- Prepublication history for this paper is available online. To view these files, please visit the journal online (http://dx.doi org/10.1136/bmjopen-2020040627).

Received 18 May 2020 Revised 14 October 2020 Accepted 15 0ctober 2020
Check for updates

(C) Author(s) (or their employer(s)) 2020. Re-use permitted under CC BY-NC. No commercial re-use. See rights and permissions. Published by BMJ.

For numbered affiliations see end of article.

Correspondence to

Lemma Getacher;

lemmagetacher@gmail.com

\section{ABSTRACT}

Objective To assess the prevalence of food insecurity (FI) and its predictors among lactating mothers in Ataye District, North Shoa Zone, Central Ethiopia.

Design A community-based cross-sectional study design was used.

Setting Two urban and four rural randomly selected kebeles of the Ataye District in Ethiopia.

Participants Out of 635 participants, 612 lactating mothers aged 15-49 years participated from February to April 2018. Mothers who lived for at least 6 months and above in the district were included, and mothers who were not able to respond to an interview were excluded. A single lactating mother per household was included. Lactating mothers in the households were selected using a cluster sampling technique. The number of lactating mothers found in each kebele was taken from family folder documentation.

Primary outcome The prevalence and predictors of food insecurity.

Results The prevalence of $\mathrm{Fl}$ among lactating mothers was $36.8 \%$. No formal education (adjusted OR (AOR) $=1.82,95 \% \mathrm{Cl} 1.13$ to 2.92$)$, no income-generating activities ( $\mathrm{AOR}=3.39,95 \% \mathrm{Cl} 2.05$ to 5.64), no home gardening practice (AOR=5.65, 95\% $\mathrm{Cl} 3.51$ to 9.08 ), alcohol use by husbands ( $\mathrm{AOR}=2.02,95 \% \mathrm{Cl} 1.25$ to 3.24 ), low minimum dietary diversity score ( $A O R=2.94$, $95 \% \mathrm{Cl} 1.88$ to 4.57 ), less than three frequencies of meals (AOR=3.97, 95\% Cl 1.65 to 9.54) and three meals only per day ( $\mathrm{AOR}=1.86,95 \% \mathrm{Cl} 1.08$ to 3.17 ) were significant predictors of $\mathrm{Fl}$ of mothers.

Conclusion The prevalence of $\mathrm{Fl}$ was high in the study area. No formal education, no income-generating activities no home gardening practice, alcohol use by husbands, low minimum dietary diversity score, fewer than three frequencies of meals and three meals only per day were independent predictors of Fl. Therefore, increasing home gardening, decreasing alcohol intake, increasing dietary diversity and performing income-generating activities are highly recommended to reduce $\mathrm{Fl}$.

\section{BACKGROUND}

Food insecurity (FI) is a condition in which all people at all times do not have physical,

\section{Strengths and limitations of this study}

- This study assessed feelings of uncertainty, anxiety over food, insufficient quantity and quality of food, and reported reductions in food intake of mothers in the household.

- A multivariate analysis method was used to control for confounding variables of food insecurity (FI) during analysis.

- Probing about the event (food insecurity experience) to minimise reporting and recall bias in the last 4 weeks of duration

- Reporting bias, recall bias and seasonal variation may be the limitations of the study.

- This study used previous studies that were conducted at the household level where the respondents was a male household head due to a lack of studies conducted on mothers.

social and economic access to sufficient, nutritious and safe food to meet their dietary needs for a productive, effective and healthy life. It also exists when availability, quality and quantity of food are limited or cannot be accessed in a socially acceptable manner that promotes and maintains the health and wellbeing of individuals. ${ }^{1-5}$ It can be classified as food secure, mildly food insecure, moderately food insecure and severely food insecure. ${ }^{26}$

Currently, it has become a global challenge and affects all nations regardless of their wealth status, but it is more severe and prevalent in low-income and middle-income countries, especially in the past two decades. ${ }^{78}$ Due to the worsening of global economic conditions, FI has received increased attention worldwide. The increase of the FI situation and the lack of progress towards the WHO global nutrition targets make it imperative for countries to step up their efforts and 
to create a world without hunger and malnutrition by 2030. 7910

Lactating mothers need more nutritious and qualified food to satisfy their physical needs and their child needs because the requirements of calories and essential nutrients are high during this period. Despite the increased nutritional requirements, especially in Africa, particularly in Ethiopia, lactating mothers are extremely vulnerable to both macronutrient and micronutrient deficiencies. ${ }^{11}$ In FI conditions, mothers are more vulnerable to malnutrition. FI being a devastating problem, affects mothers and their infants everywhere in the globe. ${ }^{711}$

In several developing countries, including Ethiopia, achieving food security for all people at all times remains a great challenge. Ethiopia, which has been plagued with FI for decades, is one of the world's poorest nations with indicators showing low levels of development and increased conditions of malnutrition. ${ }^{9}{ }^{12-14}$

In summary, the prevalence of FI ranges from $17 \%$ to $83 \%$ in global countries assessed from 2012 to $2018,{ }^{11} 15-19$ from $31.3 \%$ to $91.0 \%$ in other African countries assessed from 2013 to $2017^{1020-22}$ and from $6.8 \%$ to $77 \%$ in Ethiopia assessed from 2013 to 2016 . $^{923-27}$

The major causes of FI of mothers emerged from different sources, such as lack of formal education, rural residence, poor occupational status, large family size, increased number of children under 5 years of age, absence of income-generating activities, poor dietary diversity practice and low frequency of meals per day. ${ }^{9} 12132425$ Notwithstanding that, the effect of home gardening practices and alcohol use by their husbands on the FI of mothers has not been well addressed by previous studies.

Likewise, previous studies did not address lactating mothers' feelings of uncertainty or anxiety over food, perceptions that food is of insufficient quantity, perceptions that food is of insufficient quality, reported reductions in food intake, reported consequences of reduced food intake and feelings of shame for resorting to socially unacceptable means to obtain food resources for their household members. ${ }^{1}$

Moreover, most of the previous studies only addressed the feelings and perceptions of household heads (mostly male), except for some studies that addressed the feelings and perceptions of pregnant women. This indicates that there is a dearth of studies that need to address the feelings and perceptions of lactating mothers on FI.

In addition, most of the time in the Ethiopian context, mothers are responsible for preparing and cooking food for all household members. Because of this they are well aware of the presence or absence of sufficient food for all members of the household. For this reason, lactating mothers are the best respondents for FI studies.

Furthermore, currently, there are limited findings on FI in low-income countries like Ethiopia among lactating mothers, including the study area. Therefore, the objective of this study was to assess the prevalence of FI and its predictors among lactating mothers, including factors that were not included in previous studies in Ataye District, North Shoa Zone, Ethiopia.

\section{METHODS AND MATERIALS \\ Study setting and design}

This study was conducted in Ataye District, which is 270 $\mathrm{km}$ away from Addis Ababa (the capital city of Ethiopia) and $140 \mathrm{~km}$ from Debre Berhan town (the Zonal Town of North Shoa) in central part of Ethiopia. From the 2007 national census projection, the total population of Ataye District was 110493 , and the current population was estimated to be 170425 . The district has 30 kebeles, which is the lowest administrative unit in Ethiopia (Ataye District Report, 2017). This study was conducted in two urban and four rural randomly selected kebeles in the district.

A community-based cross-sectional study design was used to determine the prevalence and predictors of FI from February to April 2018. During the study period, the source populations of the study were all lactating mothers aged $15-49$ years.

A clear description of the study title, purpose, procedure, duration, possible risks and benefits of the study were explained to each study participant. Then written informed consent was obtained from each respondent before starting the interview.

Regarding the eligibility criteria, mothers aged 15-49 years who lived for at least 6 months and above in the district were included. On the other hand, mothers who were unable to respond to an interview, were severely sick and did not volunteer to respond to the questionnaire were excluded from this study.

\section{Sample size determination and sampling techniques}

The required sample size for this study was determined and calculated using a single population proportions formula with the following assumptions: proportion of FI among lactating mothers $50 \%(0.5), \mathrm{Z}_{\mathrm{a} / 2}$ with $95 \%$ confidence level to be 1.96, margin of error to be 0.05 , non-response to be $10 \%$, and a design effect of 1.5 . Accordingly, the final calculated sample size of the study was 635 .

Regarding the sampling procedures, considering kebeles as clusters, lactating mothers in the households were selected by the cluster sampling technique. The Ataye District has 30 kebeles (6 urban and 24 rural). However, the kebeles were selected using a simple random sampling method. Based on the residence of mothers, these kebeles/clusters were classified into urban and rural areas. The sample size was allocated proportionally according to the population size of the selected urban and rural kebeles. The number of lactating mothers found in each kebele was taken from a family folder, which is documented by the health extension workers with respect to their household. Through house-to-house visits, all lactating mothers in randomly selected clusters were included in the study. In the absence of eligible mothers during the time of visit, a revisit was arranged a minimum 
of three times and finally, if they were not present, were considered non-respondents.

\section{Data collection methods and instruments}

The study data collection instruments were developed by reviewing different kinds of literature using search engines such as PubMed, Google Scholar, Hinari and The Lancet series. A structured interviewer-administered questionnaire was used to collect the data through Amharic language (local language), which was translated from the English language.

The data collectors of this study were six female grade 10 graduated students who were fluent speakers in the local language. The data collectors underwent a community-based face-to-face interview using a structured and pretested questionnaire in Amharic. The lactating mothers were informed about the details of the research during the interview period. Two health professionals who have bachelor dgree from Ataye District Hospital and Health Center were recruited for the supervision of the data collection procedure.

The variables of this study were grouped as sociodemographic variables, health service utilisation related variables, and food source and feeding practice of motherrelated variables. The sociodemographic variables were place of residence, maternal age, marital status, maternal educational status, family size, number of children under 5 years of age, maternal occupation, religion, ethnicity and sex of the household head. The health service utilisation related variables were ANC visit, place of delivery, postnatal care visit and maternal history of illness. The food source and feeding practice of mothers' related variables were inadequate dietary intake, nutrition knowledge, sources of food, home gardening practice, alcohol intake by husbands and income-generating activities.

\section{Measurements}

Household FI was measured with the Household Food Insecurity Access Scale (HFIAS), a structured, standardised and validated tool developed mainly by Food and Nutrition Technical Assistance (FANTA), to classify households as food secure or not. ${ }^{128}$ The scale is a valid tool for measuring household FI among both rural and urban areas of Ethiopia with Cronbach's $\alpha$ values of 0.76 for round 1 and 0.73 for round $2 .^{29}$

With regard to the knowledge of nutrition, we used self-reported data asking mothers about their knowledge of nutrition. It was assessed and computed based on six questions. The questions included mothers' awareness about nutrition, dietary diversity practice and taking varieties of food groups, definitions of the term varieties and types of varieties of food groups, definitions of the term nutrition and malnutrition, causes of malnutrition, and consequences of malnutrition.

The previous history of illness of mothers' was assessed by self-reporting asking them whether they faced any illness in the last time or not, whereas the current illness was assessed by self-reporting and measurements such as fever check and temperatures.

To assess the antenatal visits (ANC), first the data collectors ask the mothers about their ANC follow-up as a self-reported to know the understanding level of mothers on their health service practice. To check its appropriateness, whether they attended or not, we cross-checked it from their family folder in their administrative kebeles.

\section{Operational definitions}

Lactating mothers

Mothers aged 15-49 years and having children 6-23 months old who were currently breast feeding their infant/child. ${ }^{30}$

\section{Food secure mothers}

Mothers who have experienced none of the FI (access) conditions or have just been worried, although rarely, during the past 4 weeks. ${ }^{6}$

\section{Food insecure mothers}

Mothers who are unable at all times to access food sufficient to lead an active and healthy life (includes all stages of FI; mild, moderate and severe) ${ }^{6}$

\section{Mildly food insecure mothers}

Mothers who worry about not having enough food sometimes or often and/or are unable to eat preferred foods and/or eat a more monotonous diet than desired and/ or some foods considered undesirable, but only rarely. ${ }^{6}$

\section{Moderately food insecure mothers}

Mothers who sacrifice quality more frequently, by eating a monotonous diet or undesirable foods sometimes or often, and/or have started to cut back on quantity by reducing the size of meals or number of meals, rarely or sometimes. However, they do not experience any of the three most severe conditions. ${ }^{6}$

\section{Severely food insecure mothers}

Mothers who have been forced to cut back on the meal size or number of meals often and/or experience any of the three most severe conditions (running out of food, going to bed hungry, or going a whole day and night without eating), even as infrequently as rarely. ${ }^{6}$

\section{Data quality control}

The data collection instrument was translated back to English by independent language experts in both languages to ensure its consistency, and comparisons were made on the consistency of the two versions. Before the actual data collection, the questionnaire was pretested outside the selected kebeles on $5 \%$ of the total sample size to ensure the validity of the tool. After the pretest had been done, all the necessary adjustments were made. Some of the adjustments were modifications and improvements to the questions related to knowledge on nutrition, the approach of the data collectors and the ability to review the mothers. Then, the translated, pretested and 
structured Amharic version of the questionnaire was used to collect the data.

Two days of training on theoretical and practical aspects was given to the six female grade 10 graduated students and the two supervisors. The focus areas of the training were interview techniques, ethical issues, rights of the participants, reading through all the questions and understanding them well, and ways of minimising under-reporting or over-reporting and maintaining confidentiality.

Interviews were conducted without the involvement of any person other than the respondent in an area providing adequate confidentiality and privacy. The actual data collection was closely supervised by the principal investigator and the two supervisors. The collected data were cross-checked on each day of activity for consistency, missing data and completeness.

\section{Patient and public involvement}

Patients and/or the public were not involved in the design, or conduct, or reporting, or dissemination plans of this research.

\section{Data processing and analysis}

The authors visually checked all the interview questionnaires before going in for analysis. EpiData V.4.2.0.0 software was used to code, enter and clean the data. To cross-check the data for completeness, double data entry was made by two data clerks. After doing this, the entered data were exported and analysed with Statistical Package for Social Science (SPSS) V.24 software for windows using IBM SPSS Statistics 24 Core System User's Guide. To describe the demographic, socioeconomic and maternalrelated characteristics of the respondents, simple descriptive statistics such as simple frequency distribution, measures of central tendency, measures of variability and percentages were performed. Tables and figures were used to present the information of respondents.

The outcome variable (FI) was determined by computing nine standard HFIAS questions adapted from the FANTA project. The tool consists of nine questions that show frequency of occurrence and measures the severity of FI in the last 4 weeks in terms of Likert Scale question responses $(0=$ never, $1=$ rarely ( 1 or 2 times), $2=$ sometimes $(3-10$ times $), 3=$ often $(>10$ times $))$. The mothers were expected to answer these questions on behalf of all household members in their household. This tool was used to assess access to food for all household members at the time of data collection. To determine the cumulative score of FI among mothers, the nine items ranged from 0 to 27 , and a higher score indicated that the household members experienced more FI.

For analysis, all 'Yes' responses were coded in ' 1 ' and 'No' responses were coded in ' 0 ', and the responses were summed to obtain the household FI status. The HFI status, which had high internal consistency (Cronbach's $\alpha=0.927$ ), was further dichotomised as 'food insecure' and 'food secure' households, which were coded as ' 1 ' and ' 0 ', respectively, for analysis.

Related to the analysis of knowledge of nutrition, using a mean score, mothers who scored above the mean cutoff point were considered to have good knowledge and coded as ' 1 ', whereas those who scored below this cutoff point were considered to have poor knowledge and coded as ' 0 '.

To see the association between each independent variable and the outcome variable, the bivariate analysis and crude OR along with a 95\% CI were used. In addition, independent variables with a value of $\mathrm{p} \leq 0.25$ were included in the multivariate analysis to control for confounding factors.

To see the linear correlation among the independent variables, multicollinearity was checked using SE. Variables with an SE of $\geq 2$ were dropped from the multivariate analysis. The test coefficient of Hosmer-Lemeshow's goodness-of-fit model was used to test the fitness of the model which was found to be insignificant with a large $p$ value $(\mathrm{p}=0.860)$.

To identify the predictors of FI, adjusted ORs (AORs) along with $95 \%$ CIs were estimated using multivariate logistic regression analysis. All tests were two-sided and the level of statistical significance was declared at a value of $\mathrm{p}<0.05$.

\section{RESULTS}

\section{Sociodemographic characteristics of respondents}

Out of 635 respondents, 612 responded to the interview resulting in a response rate of $96.23 \%$. The nonparticipation was due to the absence of study participants during different visits at the time of data collection. The mean age of the mothers $( \pm \mathrm{SD})$ was $30.61( \pm 6.44)$ years. Of the total mothers, 398 (65\%) were rural by residence, $331(54.1 \%)$ were in the age group of $15-30$ years, 526 (85.9\%) were Orthodox Tewahido Christian by religion, $547(89.4 \%)$ were Amhara by ethnicity, 482 (78.8\%) were married, $494(80.7 \%)$ were male household heads, 250 (40.8\%) had no formal education and $374(61.1 \%)$ were housewives by their occupation (table 1).

\section{Health service utilisation of mothers}

More than half of the mothers $(56.9 \%)$ had at least four ANC visits. On the other hand, nearly half of the mothers $(47.9 \%)$ delivered in the health centre and $46.7 \%$ of them had postnatal care follow-up. Three-tenths of the mothers had an illness in the last 2 weeks (table 2).

\section{Food source and feeding practice of mothers}

The main source of food for the mothers was their own production $(346(56.5 \%))$. Nearly three-fifths of the mothers had home gardening practice in their yard. In addition, more than two-thirds $(68.8 \%)$ of the mothers had three frequencies of meals per day. Regarding the knowledge of nutrition, minimum dietary diversity score and income-generating activity, 344 (56.2\%), 308 (50.3) 
Table 1 Sociodemographic characteristics of respondents in Ataye District, $2018(n=612)$

\begin{tabular}{|c|c|c|}
\hline Variables & Category & Frequency (\%) \\
\hline \multirow[t]{2}{*}{ Residence } & Urban & $214(35)$ \\
\hline & Rural & $398(65)$ \\
\hline \multirow[t]{3}{*}{ Age, years } & $15-30$ & $331(54.1)$ \\
\hline & $31-45$ & $274(44.8)$ \\
\hline & $>45$ & $7(1.1)$ \\
\hline \multirow[t]{4}{*}{ Ethnicity } & Amhara & $547(89.4)$ \\
\hline & Oromo & $49(8.0)$ \\
\hline & Tigrai & $11(1.8)$ \\
\hline & Others & $5(0.8)$ \\
\hline \multirow[t]{3}{*}{ Religion } & $\begin{array}{l}\text { Orthodox Tewahido } \\
\text { Christian }\end{array}$ & 526 (85.9) \\
\hline & Muslim & $47(7.7)$ \\
\hline & Protestant & 39 (6.4) \\
\hline \multirow[t]{5}{*}{ Marital status } & Single & $39(6.4)$ \\
\hline & Married & $482(78.8)$ \\
\hline & Divorced & $54(8.8)$ \\
\hline & Widowed & $26(4.2)$ \\
\hline & Separated & $11(1.8)$ \\
\hline \multirow{2}{*}{$\begin{array}{l}\text { Sex of household } \\
\text { head }\end{array}$} & Male & $494(80.7)$ \\
\hline & Female & 118 (19.3) \\
\hline \multirow{5}{*}{$\begin{array}{l}\text { Educational } \\
\text { status }\end{array}$} & No formal education & $250(40.8)$ \\
\hline & Read and write & $133(21.7)$ \\
\hline & Primary education & $98(16)$ \\
\hline & Secondary education & $51(8.3)$ \\
\hline & $\begin{array}{l}\text { More than secondary } \\
\text { education }\end{array}$ & $80(13.1)$ \\
\hline \multirow{6}{*}{$\begin{array}{l}\text { Occupational } \\
\text { status }\end{array}$} & Housewife & $374(61.1)$ \\
\hline & Merchant & $74(12.1)$ \\
\hline & Daily labourer & $54(8.8)$ \\
\hline & Government employee & $54(8.8)$ \\
\hline & Self-employed & $52(8.5)$ \\
\hline & Others & $4(0.7)$ \\
\hline \multirow[t]{3}{*}{ Family size } & $1-3$ & $131(21.4)$ \\
\hline & $4-6$ & $339(55.4)$ \\
\hline & $>6$ & $142(23.2)$ \\
\hline \multirow{2}{*}{$\begin{array}{l}\text { Number of } \\
\text { children under } 5 \\
\text { years of age }\end{array}$} & $1-2$ & $580(94.8)$ \\
\hline & $>2$ & $32(5.2)$ \\
\hline
\end{tabular}

and 346 (56.5) had good knowledge, high minimum dietary diversity score and income-generating activity, respectively (table 3 ).

\section{Prevalence of Fl status}

In this study, more than three-fifths of the mothers (387 $(63.2 \%))$ were food secure whereas 225 (36.8\%) were food insecure (figure 1). Of the nine HFIAS items,
Table 2 Health service utilisation of mothers in Ataye District, 2018 ( $n=612)$

\begin{tabular}{lll}
\hline Variables & Category & Frequency (\%) \\
\hline Number of ANC visits & No visit & $106(17.3)$ \\
& Up to three & $348(56.9)$ \\
& At least four & $158(25.8)$ \\
Place of delivery & Home & $201(32.8)$ \\
& Health centre & $293(47.9)$ \\
Postnatal care follow- & Yes & $118(19.3)$ \\
up & No & $286(46.7)$ \\
Presence of illness in & Yes & $326(53.3)$ \\
the last 2 weeks & No & $180(29.4)$ \\
\hline
\end{tabular}

ANC, antenatal care.

worry about food $(37.3 \%)$, unable to eat preferred foods $(30.9 \%)$ and eat just a few kinds of foods $(22.5 \%)$ were the most frequently reported occurrences of FI items in mothers (table 4).

\section{Predictors of Fl among mothers}

In the bivariate logistic regression analysis, sex of household head, educational status, number of children under 5 years of age, alcohol use, income-generating activities, postnatal follow-up, main source of food, home gardening practice, meal frequency, knowledge of nutrition and minimum dietary diversity score were associated with FI

Table 3 Food source and feeding practice of mothers in Ataye District, $2018(\mathrm{n}=612)$

\begin{tabular}{llc}
\hline Variables & Category & Frequency (\%) \\
\hline Source of food & Own production & $346(56.5)$ \\
& Purchasing & $256(41.8)$ \\
& Food aid/relief & $8(1.3)$ \\
& Other sources & $2(0.3)$ \\
Home gardening & Yes & $352(57.5)$ \\
practice & No & $260(42.5)$ \\
Use alcohol & Yes & $171(27.9)$ \\
& No & $441(72.1)$ \\
Meal frequency & Less than three meals & $47(7.7)$ \\
& Three meals & $421(68.8)$ \\
Knowledge of & Poor & $144(23.5)$ \\
nutrition & Good & $268(43.8)$ \\
Minimum dietary & Low ( $\leq 5$ food groups) & $304(49.7)$ \\
diversity score & High ( $\geq 5$ food groups) & $308(50.3)$ \\
Income- & Yes & $346(56.5)$ \\
generating & No & $266(43.5)$ \\
activity & & \\
\hline & & $344(56.2)$ \\
\hline
\end{tabular}




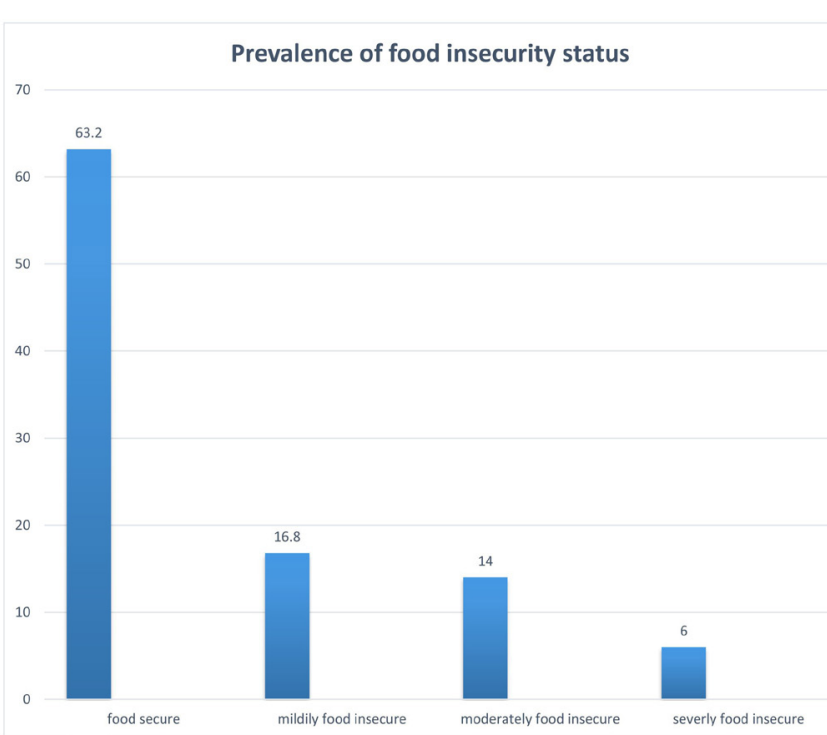

Figure 1 Food security status of mothers in Ataye District, 2018.

of mothers and became candidates for further multivariate analysis (table 5).

Using the enter method, those variables with a value of $\mathrm{p} \leq 0.25$ in the bivariate logistic regression analysis were entered into a multivariate logistic regression analysis to identify the independent predictors of FI. Accordingly, no formal education, alcohol use by husbands, no incomegenerating activities, no home gardening practice, low minimum dietary diversity score, and meal frequency less than three and three meals only were the significant predictors of FI of mothers (table 5).

Mothers who had no formal education were 1.82 times (AOR $=1.82,95 \%$ CI 1.13 to 2.92 ) more likely to have FI than those who had formal education. Regarding incomegenerating activities, mothers who had no incomegenerating activities were 3.39 times $(\mathrm{AOR}=3.39,95 \% \mathrm{CI}$ 2.05 to 5.64 ) more likely to be food insecure than their counterparts (table 5).
On the other hand, the odds of FI were 5.65 times higher among mothers who had no home gardening practice $(\mathrm{AOR}=5.65,95 \%$ CI 3.51 to 9.08 ) than their counterparts. Lactating mothers who had a husband who used alcohol in the last month were approximately 2.02 $(\mathrm{AOR}=2.02,95 \%$ CI 1.25 to 3.24$)$ times more likely to have FI status than their counterparts (table 5).

The odds of FI were nearly three times $(\mathrm{AOR}=2.94$, $95 \%$ CI 1.88 to 4.57 ) more common among mothers who had low minimum dietary diversity scores than among mothers who had high minimum dietary diversity scores (table 5).

Concerning the meal frequency of mothers, mothers who had less than three meals and three meals only were 3.97 and 1.86 times more likely to be food insecure than those who had four meals and above (AOR=3.97, 95\% CI 1.65 to 9.54 ) and (AOR=1.86, 95\% CI 1.08 to 3.17$)$, respectively (table 5 ).

\section{DISCUSSION}

The findings of this study showed that $36.8 \%$ of mothers developed FI in the study area. This study also identifies the sociodemographic, health service utilisation related, and food source and feeding practice related factors of FI among mothers. Accordingly, no formal education, alcohol use by husbands, no income-generating activities, no home gardening practice, low minimum dietary diversity score, and meal frequency less than three and three meals only were the significant predictors of FI of mothers.

The finding of this study $(36.8 \%)$ is consistent with the study conducted in Ambo District (38.4\%). ${ }^{23}$ On the other hand, it is higher than the study conducted in Vietnam $(34.4 \%),{ }^{17}$ Canada (17\%), ${ }^{18}$ Nigeria $(31.3 \%),{ }^{22}$ and Dedo and Seqa-Chekorsa Districts in Jimma Zone $(6.8 \%) .{ }^{27}$ However, this finding is much lower than the findings of studies conducted in India $(78.9 \%),{ }^{11}$ the Urban Resettlement Colony in North India $(77.2 \%),{ }^{16}$ Iran $(44 \%),{ }^{19}$

Table 4 Descriptions of the nine items of HFIAS food access questions of mothers in Ataye District, 2018 ( $\mathrm{n}=612$ )

\begin{tabular}{|c|c|c|c|c|c|}
\hline \multirow[b]{2}{*}{ Nine HFIAS items } & \multicolumn{2}{|c|}{ Response (\%) } & \multicolumn{3}{|c|}{ Frequency of occurrence (\%) } \\
\hline & Yes & No & Rarely & Sometimes & Often \\
\hline Worry about food & 37.3 & 62.7 & 22.5 & 10.1 & 4.7 \\
\hline Eat just a few kinds of foods & 22.5 & 77.5 & 16.8 & 3.8 & 1.9 \\
\hline Eat foods they really do not want eat & 20.4 & 79.6 & 9.8 & 5.9 & 4.7 \\
\hline Eat fewer meals in a day & 8.5 & 91.5 & 5.7 & 2.6 & 0.2 \\
\hline No food of any kind in the household & 5.2 & 94.8 & 3.1 & 2.0 & 0.2 \\
\hline Go to sleep hungry & 4.4 & 95.6 & 2.6 & 1.8 & 0.2 \\
\hline Go a whole day and night without eating & 3.1 & 96.9 & 2.1 & 0.5 & 0.5 \\
\hline
\end{tabular}

HFIAS, Household Food Insecurity Access Scale. 
Table 5 Bivariable and multivariable logistic regression ${ }^{1}$ analysis of predictors of food insecurity among lactating mothers in Ataye District, $2018(\mathrm{n}=612)$

\begin{tabular}{|c|c|c|c|c|}
\hline \multirow[b]{2}{*}{ Variables } & \multicolumn{2}{|c|}{ Food security status } & \multirow[b]{2}{*}{ COR (95\% CI) } & \multirow[b]{2}{*}{ AOR $(95 \% \mathrm{Cl})$} \\
\hline & Insecure (\%) & Secure (\%) & & \\
\hline \multicolumn{5}{|l|}{ Sex of household head } \\
\hline Male & $190(35.5)$ & $304(61.5)$ & 1.00 & 1.00 \\
\hline Female & $35(29.7)$ & $83(70.5)$ & $0.67(0.44$ to 1.04$)$ & 0.80 (0.46 to 1.38$)$ \\
\hline \multicolumn{5}{|c|}{ Educational status of mothers } \\
\hline No formal education & $167(49.4)$ & $171(50.6)$ & $3.64(2.54 \text { to } 5.21)^{\star}$ & $1.82(1.13 \text { to } 2.92)^{*}$ \\
\hline Formal education & $58(21.2)$ & $216(78.8)$ & 1.00 & 1.00 \\
\hline \multicolumn{5}{|c|}{ Number of children $<5$ years of age } \\
\hline $1-2$ & $209(36)$ & $371(64)$ & 1.00 & 1.00 \\
\hline$>2$ & $16(50)$ & $16(50)$ & 1.77 (0.87 to 3.62$)$ & $1.45(0.57$ to 3.67$)$ \\
\hline \multicolumn{5}{|l|}{ Source of food } \\
\hline Own source & $160(46.2)$ & $186(53.8)$ & 1.00 & 1.00 \\
\hline No known source & $65(24.4)$ & $201(75.6)$ & 2.66 (1.87 to 3.77$)$ & $1.05(0.60$ to 1.85$)$ \\
\hline \multicolumn{5}{|c|}{ Income-generating activities } \\
\hline Yes & $81(23.4)$ & $256(76.6)$ & 1.00 & 1.00 \\
\hline No & $144(54.1)$ & $122(45.9)$ & $3.86(2.73 \text { to } 5.46)^{*}$ & $3.39(2.05 \text { to } 5.64)^{*}$ \\
\hline \multicolumn{5}{|l|}{ Frequency of meal per day } \\
\hline Less than three meals & $27(57.4)$ & $20(42.6)$ & $5.13(2.53 \text { to } 10.37)^{*}$ & $3.97(1.65 \text { to } 9.54)^{\star}$ \\
\hline Three meals & $168(39.9)$ & $253(60.1)$ & $2.52(1.62 \text { to } 3.95)^{\star}$ & $1.86(1.08 \text { to } 3.17)^{\star}$ \\
\hline More than three meals & $30(20.8)$ & $114(79.2)$ & 1.00 & 1.00 \\
\hline \multicolumn{5}{|l|}{ Postnatal care follow-up } \\
\hline Yes & $109(33.4)$ & $217(66.6)$ & 1.00 & 1.00 \\
\hline No & $116(40.6)$ & $170(59.4)$ & 1.36 (0.98 to 1.89$)$ & 0.69 (0.45 to 1.09$)$ \\
\hline \multicolumn{5}{|l|}{ Alcohol use by husband } \\
\hline Yes & $72(42.1)$ & 99 (57.9) & $1.37(0.95$ to 1.97$)$ & $2.02(1.25 \text { to } 3.24)^{\star}$ \\
\hline No & $153(34.7)$ & $288(65.3)$ & 1.00 & 1.00 \\
\hline \multicolumn{5}{|l|}{ Home garden practice } \\
\hline Yes & $46(17.7)$ & $241(82.3)$ & 1.00 & 1.00 \\
\hline No & 179 (50.9) & $173(49.1)$ & $4.82(3.29 \text { to } 7.04)^{*}$ & 5.65 (3.51 to 9.08$)^{\star}$ \\
\hline \multicolumn{5}{|l|}{ Knowledge of nutrition } \\
\hline Poor & $121(45.1)$ & $147(54.9)$ & 1.90 (1.36 to 2.65$)$ & 0.19 (0.51 to 1.26$)$ \\
\hline Good & $104(30.2)$ & $240(69.8)$ & 1.00 & 1.00 \\
\hline \multicolumn{5}{|c|}{ Minimum dietary diversity score } \\
\hline Low & $160(52.6)$ & $144(47.4)$ & $4.15(2.91 \text { to } 5.92)^{*}$ & $2.94(1.88 \text { to } 4.57)^{\star}$ \\
\hline High & $65(21.1)$ & 243 (78.9) & 1.00 & 1.00 \\
\hline
\end{tabular}

${ }^{1}$ in table caption indicates the model fitness.

*1 Hosmer-Lemeshow test (0.86).

$\dagger^{*} \mathrm{P}<0.001$

AOR, adjusted OR; COR, crude OR; HFI, Household Food Insecurity; MDD, Minimum Dietary Diversity; PNC, postnatal care.

Malesia $(83.9 \%){ }^{15}$ Tanzania in two seasons $(80 \%$ and $69 \%)$ during the long rainy season and immediately after the harvest season, ${ }^{10}$ South Africa Limpopo Province $(53 \%),{ }^{21}$ South Africa $(91 \%),{ }^{20}$ Farta District $(70.7 \%),{ }^{9}$ Babile District $(57 \%),{ }^{24}$ Benshangul Gumuz Region $(72 \%),{ }^{26}$ Shashemene $(55.7 \%)^{25}$ and Bule Hora District $(77 \%){ }^{12}$
These inconsistencies could be due to the differences in some sociodemographic characteristics of the study participants. Since this study was done in the postharvest season and the other studies have a preharvest season, seasonal variation may be another important factor for the perceived difference. 
Regarding the predictors of FI of mothers, the odds of FI were nearly twofold higher among mothers who had no formal education than those who had formal education. This is in line with the study conducted previously in the rural areas of Ethiopia (Farta District and Babile District) and South Africa in a community-based setting. ${ }^{921}{ }^{24}$ This is because mothers who have no formal education may not have good knowledge to understand how to grow, improve, manage and produce enough types of farms to sustain the food security status of their households and of themselves.

FI was nearly fourfold more common in mothers who had no income-generating activities than in mothers who had income-generating activities. This is similar to the study conducted in Bule Hora District, Babile District, Farta District and Belo-Jinganfoy District. ${ }^{9} 122426$ This is because mothers who have no income-generating activities (off-farm sources) cannot challenge FI unless they have an additional source of food in the absence of food in the household.

Lactating mothers who had husbands who used alcohol were two times more likely to have FI than their counterparts. This is because mothers who have husbands spending much money on alcohol drinking will be highly exposed to FI. To date, the association between FI and alcohol use is not supported by previous studies.

The odds of FI were six times higher among mothers who had no home gardening practice than their counterparts. Those mothers who had no practice in a home garden in their compound will have a high probability of developing FI, because they cannot easily access different types of vegetables, fruits and other important crops in their backyard, in case they cannot prevent temporal FI. To date, it is not supported by previous evidence.

The odds of FI were nearly three times more common among mothers who had low minimum dietary diversity scores than mothers who had high minimum dietary diversity scores. This is supported by the study conducted in Tanzania. ${ }^{10}$ This is because mothers who had not taken different groups of food indirectly indicate that they have no good food security status in their household.

Regarding the mothers' meal frequency, mothers who had up to two meals and three meals were four times and two times more likely to have FI than those who had four meals and above, respectively. This is consistent with the study done in north-western Ethiopia. ${ }^{13}$ If lactating mothers do not have at least two meals more than they usually take, they are highly at risk of developing undernutrition. This directly indicates that FI is the direct cause of malnutrition for mothers and thereby for their children.

Thus, the government of Ethiopia, particularly the Ataye District Health Office, should design intervention programmes aimed at improving maternal food security status through appropriate food-based approaches for mothers to have good coping strategies. In addition, the district should strengthen nutrition education programmes, creating strong multisectoral collaboration targeted at improving the mother's educational status, home gardening practice, income-generating activities and dietary diversity practice. Since FI has multiple factors, a further study with a stronger study design, like a prospective cohort study, is needed to identify other independent predictors of FI in mothers in different seasons.

Related to the methodological limitations of the study, the cross-sectional study design inhibits any causal inferences between FI and its predictors. This study design cannot generate the temporal relationship between the outcome variable and the correlates.

On the other hand, seasonal variation may be one of the limitations of the study since this study was conducted in the postharvest season of Ethiopia. Even if self-reporting and dietary recall are very common and effective means of collecting data in nutrition and epidemiological studies, especially in resource-poor countries like Ethiopia, the self-reported nature and a 1 month recall of data collection for FI and a 24 hours recall for dietary diversity make the information prone to social desirability bias, reporting bias and recall bias, which underestimates the power of the study. These biases were minimised by probing and giving detailed information about the event. Another limitation is that this study uses previous studies that were conducted at the household level with male household head respondents due to the lack of studies conducted on mothers, which may not be the real comparator of this study.

\section{CONCLUSIONS}

The prevalence of FI was high among the study participants in the study area. No formal educational status of mothers, alcohol use by husband, no income-generating activities, no home gardening practice, decreased meal frequency and low minimum dietary diversity score were the significant predictors of FI of mothers.

\section{Author affiliations}

${ }^{1}$ Department of Public Health, College of Health Sciences, Institute of Medicine and Health Sciences, Debre Berhan University, Debre Berhan, Ethiopia

${ }^{2}$ School of Public Health, College of Health Sciences, Addis Ababa University, Addis Ababa, Ethiopia

${ }^{3}$ Department of Nursing, College of Health Sciences, Institute of Medicine and Health Sciences, Debre Berhan University, Debre Berhan, Ethiopia

${ }^{4}$ Department of Nursing, College of Health Sciences, Institute of Medicine and Health Sciences, Mizan-Tepi University, Mizan, Ethiopia

${ }^{5}$ Department of Nutrition, School of Public Health, College of Health Sciences, Dilla University, Dilla, Ethiopia

${ }^{6}$ Department of Public Health, College of Medicine and Health Sciences, Wolkite University, Wolkite, Ethiopia

${ }^{7}$ Department of Pediatrics and Neonatal Nursing, College of Health Sciences, Debre Tabor University, Debre Tabor, Ethiopia

${ }^{8}$ Department of Public Health, College of Health Sciences, Debre Markos University, Debre Markos, Ethiopia

Acknowledgements The authors thank the Ataye District Health Office, kebele administrators and health extension workers for their support and for providing them with the necessary information on the study kebeles. The authors also thank the study participants, data collectors, supervisors and language translators for their contribution to this study. 
Contributors LG: Participated in the conception and design of the study, performed the data collection, performed the statistical analysis and served as the lead author of the manuscript. GE: Participated in the design of the study, revised subsequent drafts of the paper and contributed to the finalisation of the manuscript. AM, YAA, SD, HA, AT and WAB: Assisted in the design of the study, statistical and intellectual analysis, and revised subsequent drafts of the manuscript. All authors read and approved the final manuscript.

Funding The authors have not declared a specific grant for this research from any funding agency in the public, commercial or not-for-profit sectors.

Competing interests None declared.

Patient consent for publication Obtained.

Ethics approval Ethical approval was obtained from the College of Health and Medical Science Institutional Health Research Ethics Review Committee (IHRERC) of Haramaya University on 15 January 2018 (number Ref C/AC/R/D/897/18).

Provenance and peer review Not commissioned; externally peer reviewed.

Data availability statement The data sets used and/or analysed during the current study are available from the corresponding author on reasonable request.

Open access This is an open access article distributed in accordance with the Creative Commons Attribution Non Commercial (CC BY-NC 4.0) license, which permits others to distribute, remix, adapt, build upon this work non-commercially, and license their derivative works on different terms, provided the original work is properly cited, appropriate credit is given, any changes made indicated, and the use is non-commercial. See: http://creativecommons.org/licenses/by-nc/4.0/.

\section{ORCID iDs}

Lemma Getacher http://orcid.org/0000-0002-9237-117X

Yared Asmare Aynalem http://orcid.org/0000-0002-3005-2296

Haimanot Abebe http://orcid.org/0000-0001-5885-5982

Wubet Alebachew Bayih http://orcid.org/0000-0003-1439-4402

Samuel Derbie Habtegiorgis http://orcid.org/0000-0002-3284-3761

\section{REFERENCES}

1 Coates J, Anne S, Paula B. Household food insecurity access scale (HFIAS) for measurement of food access: indicator guide, 2007. Available: https://journals.plos.org/plosone/article/file?id=10.1371/ journal.pone.0199511\&type=printable [Accessed 20 Dec 2018].

2 FAO, and FAD and WFP. The state of food insecurity in the world, 2015. Available: http://www.fao.org/publications/sofi/2015/en/ [Accessed 20 Dec 2018].

3 Hala G. Food security and nutrition in the context of the global nutrition transition, 2014. Available: https://www.semanticscholar.org/ paper/Food-Security-and-Nutrition-in-the-context-of-the-Ghattas/ fa911f068031fe667fe7cd7ae50a0aa12e5d914 [Accessed 20 Dec 2018].

4 Leroy JL, Ruel M, Frongillo EA, et al. Measuring the food access dimension of food security: a critical review and mapping of indicators. Food Nutr Bull 2015;36:167-95.

5 Tarasuk V. Implications of a basic income guarantee for household food insecurity, 2017. Available: https://proof.utoronto.ca/wpcontent/uploads/2017/06/Paper-Tarasuk-BIG-EN-17.06.13-1712.pdf

6 Coates J, Anne S, Paula B. Household food insecurity access scale (HFIAS) for measurement of food access: indicator guide version 3. Washington, DC: Food and Nutrition Technical Assistance Project, Academy for Educational Development, 2007. https://journals.plos. org/plosone/article/file?id=10.1371/journal.pone.0199511\&type= printable

7 FAO. Regional overview of food security and nutrition. addressing the threat from climate variability and extremes for food security and nutrition, 2018. Available: http://www.fao.org/3/a-i7967e.pdf [Accessed 20 Dec 2018].

8 Mathys E, Zeina MM. Usaid office of food for peace Usaid office of food for peace food security country framework, 2019. Available: https://www.fantaproject.org/sites/default/files/resources/FSCFMadagascar-2013-web.pdf [Accessed 20 Dec 2018].
9 Endale W, Mengesha Z, Atinafu A, et al. Food insecurity in Farta district, Northwest Ethiopia: a community based cross-sectional study. BMC Res Notes 2014;7:130-6.

10 Ntwenya JE, Kinabo J, Msuya J, et al. Dietary patterns and household food insecurity in rural populations of Kilosa district, Tanzania. PLoS One 2015;10:e0126038-13.

11 Payne HE, Bobbi G, Siena FD, et al. Factors associated with food insecurity among women and children in rural Rajasthan, India. J Gender Agriculture Food Security 2016;1:23-39.

12 Abdulla AM. Determinants of household food security and coping strategies: the case of Bule-Hora district, Borana zone, Oromia, Ethiopia. Eur J Food Sci Technol 2015;3:30-44.

13 Alem $\mathrm{H}$. Transitory food insecurity and coping strategies in northwestern Ethiopia, 2014. Available: https://www.researchgate.net/ publication/262417159 [Accessed 20 Dec 2018].

14 Belachew T, Lindstrom D, Gebremariam A, et al. Predictors of chronic food insecurity among adolescents in Southwest Ethiopia: a longitudinal study. BMC Public Health 2012;12:1.

15 Ihab AN, Rohana AJ, Wan Manan WM, et al. Association of household food insecurity and adverse health outcomes among mothers in low-income households : a cross-sectional study of a rural sample in Malaysia. J Health Popul Nutr 2012;4:1971-87.

16 Chinnakali P, Upadhyay RP, Shokeen D, et al. Prevalence of household-level food insecurity and its determinants in an urban resettlement colony in North India. $J$ Health Popul Nutr 2014;32:227-36.

17 Vuong TN, Gallegos D, Ramsey R. Household food insecurity, diet, and weight status in a disadvantaged district of $\mathrm{HO}$ Chi Minh City, Vietnam: a cross-sectional study. BMC Public Health 2015;15:1-10.

18 Orr SK, Dachner N, Frank L, et al. Relation between household food insecurity and breastfeeding in Canada. CMAJ 2018;190:E312-9.

19 Kazemi F, Moafi F, Samiei Siboni F, et al. Prevalence and predictors of food insecurity among pregnant women: a cross sectional study in Qazvin Province, Iran. Midwifery 2018;66:25-9.

20 Grobler WCJ. Food insecure household coping strategies: the case of a low income neighborhood in South Africa. Mediterr J Soc Sci 2014;5.

21 De Cock N, D'Haese M, Vink N, et al. Food security in rural areas of Limpopo Province, South Africa. Food Secur 2013;5:269-82.

22 Olayiwola S, Yuniyus DG. Analysis of food security status and coping strategies among rural households in Oluyole local government area of Oyo. FUW Trend Sci Technol J 2017;2:28-32.

23 Zerihun E, Gudina E, Firehiwot M. Under nutrition and its associated factors among lactating mothers in rural Ambo district, West Shewa zone, Oromia region, Ethiopia. East African J Health Biomed Sci 2016;1:39-48.

24 Bimerew TG, Fekadu B. Factors influencing rural household food insecurity : the case of Babile District, East Hararghe Zone. J Dev Agric Econ 2014;6:149-58.

25 Mitiku A, Bekabil F, Beyene T. Empirical analysis of the determinants of rural households food security in Southern Ethiopia : the case of Shashemene District. Basic Res J Agric Sci Rev 2013;1:132-8.

26 Guyu FD, Muluneh W. Determinants of seasonal food insecurity in the green famine belt of Ethiopia: the case of households in Belo-jiganfoy district, Benishangul-gumuz region. Afr J Food Sci 2016;10:278-91.

27 Alemayehu M, Alemayehu A, Abebe G. Factors associated with malnutrition among lactating women in Subsistence farming households from Dedo and Seqa-Chekorsa districts, Jimma zone, 2014. Develop Country Stud 2015;5.

28 Deitchle M, Terri B, Swindale A, et al. Validation of a measure of household hunger for cross-cultural use. Washington, DC: food and nutrition technical assistance II project (FANTA-2), AED, 2010. Available: https://www.fantaproject.org/sites/default/files/resources/ HHS_Validation_Report_May2010_0.pdf [Accessed 20 Dec 2018].

29 Hagos S, Lunde T, Damen H, et al. Is the adapted household food insecurity access scale (HFIAS) developed internationally to measure food insecurity valid in urban and rural households of Ethiopia? BMC Nutrition 2015;1.

30 Haileslassie K, Mulugeta A, Girma M, Afework M, Meron G. Feeding practices, nutritional status and associated factors of lactating women in Samre Woreda, South eastern zone of Tigray, Ethiopia. Nutr J 2013;12:28. 